\title{
Thinking about the Future: How Do Young People Deal with Money?
}

\author{
Claudia Mont'Alvão* Pedro Bevilaqua and Raquel Cappelletto \\ LEUI Laboratory of Ergodesign and Usability of Interfaces \\ Graduate Program in Design, Pontifical Catholic Univ. of Rio de Janeiro \\ Rio de Janeiro, Brazil \\ E-mail: cmontalvao@puc-rio.br
}

\begin{abstract}
The world population is changing and ageing. And young adults? Are they prepared to be an older adult? How to deal with expectations for life and financial aspects in the long term? These are the questions discussed in this paper, gathering information design, financial literacy, and human factors. A descriptive approach considered a literature review of financial education and literacy, consumer consumption by adolescents and young adults, and how human factors specialists discuss this topic. Based on this information, both qualitative and quantitative research with young adults on their financial literacy was conducted to investigate young adults' perspectives on their future, decision-making about money now, and retiring. Data results pointed out a view, and some solutions are proposed as the next steps.
\end{abstract}

Keywords: financial education, young adults, information comprehensibility, design for education 


\section{$\Lambda$ Macrothink}

\section{Introduction}

At the begging of this century, Greenspan (2002) wrote about financial literacy and the progress in America, 'more access to financial information and instruments will help less-well-off households and businesses to flourish".

This context leads us to an understanding of financial literacy. It is not a general or easy concept once several terms as financial education, financial knowledge, financial literacy, and health literacy are used. Huston (2010) suggests that financial literacy could be defined as measuring how well an individual can understand and use personal finance-related information. This author relates financial literacy, knowledge, education, behaviour, and well-being.

According to Lusardi (2015), young people must make critical decisions early in life, such as going to college and finance that education. From this author's point of view, these financial decisions increase in individual responsibility and have implications not just for individuals but also for society. Lusardi also questions if individuals are well-equipped to make these types of decisions.

Lusardi and colleagues (2017) highlight that given the pressing need to improve financial literacy among individuals, financial education programs have become an essential research topic. Authors also affirm that 'work has also focused on financial education for young adults.' Some researches were also mentioned by Lusardi et al. (2017) and are summarized here support this affirmative:

* Walstad et al. (2010), about financial education program on high school student's knowledge of personal finance;

* Carlin and Robinson (2012a, 2012b) about the achievement of the research with this profile of consumer;

* The experiment of Bechetti et al. (2013) to study the effect of financial education on investment attitudes in a large sample of high school students in Italy;

* The debt behaviour discussed by Brown et al. (2013) suggests that financial education programs, increasingly promoted by policymakers, do have significant impacts on the financial decision-making of youth; and

* Aspects of teaching a short financial education program on teenagers in German high schools in Lührmann et al. (2015).

From the information design point of view, it is fundamental to understand the role and importance of the design process in this scenario, which leads us to some questions: how can the information presented relate to the comprehension? Do young adults understand the information available about financial products?

\section{HF/E and Information Design}

Talking about financial literacy is talking about information design and human factors. 
Leaflets, websites, among other promotional pieces, are sources for financial education and decision-making. Previous research finds that interactions - with peers, family, culture, and media-shape young people's financial knowledge, particularly their attitudes as consumers (Ali et al., 2014).

As information design,' the twinned disciplines of human factors and ergonomics (HF/E) have often been characterized as the sciences concerned with the "fit" between the worker and their task. From its earliest instantiations and persisting into the present, this fit has been principally concerned with a match between the worker's spatial characteristics and the task's physical demands, all set within the context of the workplace'. (Hancock, 2018)

According to (Dul et al., 2012), there are three fundamental characteristics of HFE: HFE takes a systems approach, is design-driven, and focuses on two related outcomes: performance and well-being.

The focus of HFE is to improve performance and well-being by designing the integrative whole better and integrating the human into the system better. (DUL et al., 2012). According to this author, "HFE seeks to improve performance and well-being through systems design. Analyses and assessments result in recommendations and actions for this design."

Considering the role of $\mathrm{HF} / \mathrm{E}$ in the information design area, this paper investigates young adults' profile and their relations and expectancies with money and comprehensibility of the information offered about financial products by financial institutions.

\section{The context: a literature review}

As expected, information, quality, and presentation methods are a topic of concern for references mainly in Law, Economics, Mathematics, Social Behavior, and Education journals.

Bandura (1989) presents some topics associated with $\mathrm{HF} / \mathrm{E}$ as the social cognitive theory, as self-efficacy expectations influence behaviour change. Perceived self-efficacy is the belief in one's own ability to perform successfully in a situation.

Lusardi (2012) points out that individuals often struggle with processing information that requires extensive calculations - this type of processing requires a high numeracy level, which many individuals do not have.

Another critical indicator was affirmed by Huston (2010), that literature on the cause and effect relationship between financial education and financial literacy is particularly limited. To be financially literate, individuals must demonstrate the knowledge and skills needed to make choices within a financial marketplace that all consumers face regardless of their particular characteristics.

Ali et al. (2014) discuss the contexts for financial decision-making. According to these authors, "financial decision-making is recognized as being influenced by one's social and economic circumstances and family and peers," and previous research finds that "interactions with peers, family, culture, and media shape the financial knowledge of young people, particularly their attitudes as consumers." 


\section{Mll Macrothink}

The information design presented to consumers of financial products has a direct relation with decision making. Since 2005, the OECD established that it is essential that financial institutions check if clients/ consumers comprehend all information offered.

Authors, as Lowe and Arnett (2020), affirm that while financial independence is a crucial criterion for adulthood, few emerging adults have attained it. This author points out that " $60 \%$ of a national sample of American emerging adults (ages 18-29 years) received financial support from parents ranging from "occasional" to "regular support for living expenses" (Arnett \& Schwab, 2012). Generally, American parents provide on average \$38,340 to their child from ages 18 to 34 years, which has increased since the 1970s (Schoeni \& Ross, 2005), and most agree they have a responsibility to provide financial assistance to their adult child (Parker \& Patton, 2013)."

Considering the authors cited above and many others, it was clear that financial literacy and young adults' financial education is a topic that matters worldwide.

To complete the context in which this research is being carried out, an essential aspect of financial education was the information from Inaf (2018). This report shows impressive numbers of literacy and reading skills of the Brazilian population:

$.8 \%$ is considered illiterate, once are unable to read and write.

. $12 \%$ is at a rudimentary level, which means, can find one or more explicit information, expressed literally, in straightforward texts like calendars, simple tables, and informative posters.

. 34\% can be considered at the elementary level, once can select one or more units of information, observing certain conditions, in diverse texts of medium length, performing small inferences.

. $25 \%$ are in intermediate level, once are capable of finding the expressed information literally in either journalistic or scientific texts, performing small inferences.

. Finally, $12 \%$ can be considered at the proficiency level. Citizens in this profile understand documents of greater complexity based on elements of a given context and can provide an opinion on the author's positioning or style.

So, if people can barely understand the daily information, are most of this population prepared to deal with financial products?

A UNESCO report, published in 2019, highlights that the number of non-literate adults, aged 15 and over, in Brazil achieved 13,044,000 people.

Different numbers are presented by the Brazilian National Institute of geography and Statistics, IBGE, which showed in 2019, a total of 11,3 million people illiterate people aged 15 or over, $6,8 \%$ of the total population.

Financial education, financial literacy, self-efficacy, numeracy, financial decision making, quality of information - must be considered during this topic and the information design 
process.

This research focused on young adults, users, consumers of financial information, trying to answer some aspects highlighted by the literature review that is related to $\mathrm{HF} / \mathrm{E}$ :

- Are young adults' literate' from the 'financial point of view'?

- How do they behave, feel, and think about money and the future?

\section{Method}

Four-phase descriptive research was set as a method to answer the questions presented above:

1) literature review on financial education/ literacy, information design and research in this area.

2) qualitative and quantitative research with young people on their financial literacy.

3) experimental research using eye-tracking for analysis of comprehensibility of financial information.

In this paper, phases (1) and (2) will be presented and their results.

Phase one, literature review results, was presented to introduce this paper and was used to define phase (2), both qualitative and quantitative research.

Initial work was necessary to define the age groups to take part in this research. Papers and reports consulted and presented here show a different range of ages for 'young adults.'

For example, the OECD's International Assessment of Adult Competencies (PIAAC) shows how languages matter to literacy proficiency and adults' information-processing skills, considering subjects from 16 to 65-year-olds (OECD, 2019).

In the same year, UNESCO (2019) present results about the adult literacy rate in different countries mentioning 15 and over.

The team first considered in this research the age range of 15 to 29 y. o., as presented in the next topic.

As a qualitative step, semi-structured interviews were carried out with young adults. Questions considered their relationship with the financial education topic and their perception of its products' available information in the financial market. The intention was to find out which are the source of information for these young adults, how they 'learned' to deal with finances, if they had some formal financial education, if there were 'problems with money' which were the main ones, and how concerned about the money they are today, and about the future.

After considering the interviews' answers, a field survey was carried out as a quantitative approach through an online questionnaire. It included:

(a) three questions proposed by Lusardi and Mitchell (2007). 
(b) two questions presented by Lusardi and Mitchell (2011).

(c) aspects of financial literacy based on references and others to set a profile; such as having their own money, financial decision-making, and how financial matters "fit into" their thoughts and decisions about the future - also considered by Ali et al. (2014).

These questions were presented in the form of a multiple-choice and 28 as a Likert scale. The form also included answers for gender, age, and one word that defines the respondent as a consumer.

\section{Results}

The literature review achievements were the basis for the next phase of this research, a qualitative approach.

Once the Brazilian Ethics Code defines that and youth below 21 cannot answer a questionnaire without a tutor's accordance, this research explained the minimum age of 21 years old and understand that most of the students are in university at this age. In this case, 'Consent terms' must be signed for those volunteers older than 21 years old. For younger, it is necessary the agreement of a tutor and is called 'Term of Assent,' and they were not included in the sample of this research. The top of the range was also considered 29 y.o., once is the same used by the indicators of OECD (2019) report about Brazilian education.

So, the interviews were conducted with volunteers aged $21-29$ years old.

\subsection{Interviews}

A total of 12 volunteers ( 7 males and 5 females) participated $(\mathrm{M}=23,83$ years; $\mathrm{SD}=2,62)$. The majority $(\mathrm{n}=8)$ affirmed that they were not 'taught' about finances and mentioned that they do not remember formal financial education. Other volunteers $(n=4)$ cited that remembering math problems at school related to money, like percentage calculation.

When asked about how they deal with money, problems dealing with money and perspectives for the future, answers were divided into two groups: not employed and employed. Not-employed volunteers $(n=7)$ say they receive a monthly amount from family to personal expenses, and what they gain, they spend. So, they do not have problems at all. If the money ends, some of them $(n=3)$ can ask for the amount for the next month. So, the strategy is to think about the priorities, to avoid a new month without money. By now, the majority of this group $(n=6)$ is not concerned about the future. They believe they will be more concerned when they have their own money and will need to deal with different expenses. Answers indicated that they talk about finances with family, friends, or search on the internet.

Employed volunteers have a different relationship with money, once they cannot ask for more. Pay the bills to come first, in something lasts; they usually spent on entertainment. Furthermore, if there are no expenses with entertainment, they spare for the next month. However, it is not precisely concern about the future, but with the 'near future.'

The results point out that all of them use debit cards linked with bank accounts considering both employed and not employed answers. They think it safer than having cash; once the card 
is lost, no one can use it.

\subsection{Questionnaire}

A pre-test was with eight volunteers was applied. Even it was an online questionnaire, these volunteers accessed it online and, when completed, discussed their impression about the formulary with the research team. The aspect of lack of financial literacy was noted once during their evaluation of these questions; they find it 'funny,' or maybe 'not necessary,' but they considered that any change was necessary with the questions or answer options for future respondents.

These were young adults from 21 to 29 years old, as happened with the interview volunteers, concerning the Consent term aspects.

After checking the pre-test results, the link for the questionnaires final version was spread through personal contact on diverse places, including schools, malls, bus stations, universities, and other public places recruited from Rio de Janeiro city, Brazil.

A total of 132 participants answered the questionnaire, but just 114 forms were complete and valid. Participants were primarily workers and students. After agreeing with the consent form, participants were invited to answer the questions using a calculator, if necessary.

The first three questions were based on Lusardi \& Mitchel (2007). In question 1, "If the chance of getting a disease is $10 \%$, how many people out of 1,000 would be expected to get the disease?" had $51.8 \%$ of wrong answers and $48,2 \%$ of correct ones ( $\mathrm{n}=114)$. Answers for question 2 "If five people all have the winning number in the lottery and the prize is 2 million dollars, how much will each of them get?" the majority did it right, 77,2\%. Considering question 3, which evaluated financial literacy, "Let's say you have 200 dollars in a savings account. The account earns $10 \%$ interest per year. How much would you have in the account at the end of two years?" was suitable for the majority, $78.1 \%$.

The two subsequent questions were about basic calculations. They were "If the chance of being contaminated by a certain disease is 10 per cent, how many people, in a total of 1.000 can be contaminated?" and "If five people have the chance to win the lottery with the same number, and total prize is 2 million of Brazilian reals, how much each one will win?" Based on Lusardi \& Mitchel (2011), we had 100\% of the correct answers for both questions.

Once comparing the results of these five questions, it was clear that question 3 - which was necessary to calculate composed interest rates - was difficult for these volunteers.

Another profile result of this respondents can be summarized: the majority, 79,1\% ( $\mathrm{n}=91)$, has their own money, even they live alone $14 \%(n=16)$, with friends $3.5 \%(n=4)$, or still with the family, $82.5 \%(\mathrm{n}=94)$.

Once the formulary also presented some statements as a Likert scale, it was possible to check some other opinions related to the research questions, considering the sample. Table 1 shows the mean and standard deviation of ten out of 28 answers on the 5-point Likert scale. 


\section{Al Macrothink}

Table 1. Means agreement (and standard deviations) of statements concerning financial beliefs and behaviour in descending order (based on grand mean). Higher numbers indicate higher agreement

\begin{tabular}{ll}
\hline Statement & Mean (SD) \\
\hline $\begin{array}{l}\text { I am aware of the role of money in my future. } \\
\text { I'm worried if my purchasing power will change }\end{array}$ & $4.7(0.6)$ \\
once I get older. & \\
$\begin{array}{l}\text { This form made me think about the importance of } \\
\text { learning more about financial education. }\end{array}$ & $3.9(1.1)$ \\
$\begin{array}{l}\text { I have savings already thinking about my future. } \\
\text { Since I was a child, my parents/ tutors teach me how }\end{array}$ & $3.6(1.2)$ \\
to deal with money. & \\
$\begin{array}{l}\text { Talking about money is not common in my family. } \\
\text { I don't think what my retirement will be like when I }\end{array}$ & $2.3(1.3)$ \\
$\begin{array}{l}\text { am older. } \\
\text { I am still not worried about my financial future. }\end{array}$ & $1.2(0.5)$ \\
$\begin{array}{l}\text { Discussions like this questionnaire don't matter! The } \\
\text { important thing is to live today now! }\end{array}$ & $1.0(0.7)$ \\
\hline
\end{tabular}

Once comparing both qualitative and quantitative research results, it is possible to answer the research questions:

. Are young adults' literate' from the 'financial point of view'? In this sample, it is possible to say that the majority is literate, considering the results of the correct answers based on Lusardi \& Mitchel $(2007,2011)$ questions.

. How do these young adults behave, feel, and think about money and the future? In this sample, finances are a concern and how they will deal with money in the future.

Once most of the respondents also affirmed that family and parents are one of the primary sources of information about finances, we can also mention Ali et al. (2014). These authors declare that "the role of parental financial modelling is found to play a pivotal role in how young people manage income and negotiate debt, and studies find that discussing financial matters with parents is positively associated with greater financial literacy in adulthood." 


\section{Macrothink Institute ${ }^{\mathrm{TM}}$}

The results of the free answer to the question' Write ONE word that defines you as a consumer,' were summarized in a word cloud, presented in figure 1.

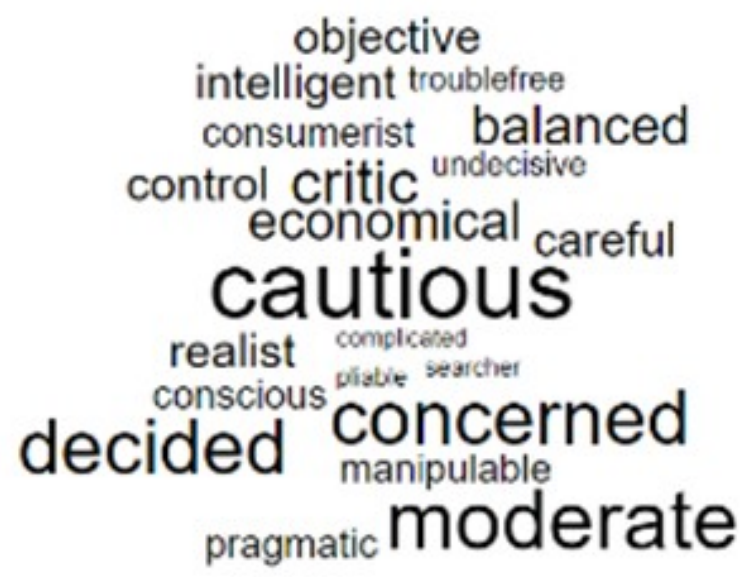

Figure 1. Word cloud with the words of consumer self-definition on studied sample

Peer influences, including the pressure to "fit in" with peer groups, are acknowledged to also play a role in young people's financial decision-making. Education is another influencing factor in the acquisition of the knowledge that shapes financial decisions. Two studies have found that high school financial literacy education changes behaviour positively concerning savings.

Briefly analyzing the results, we must say that these results are not aligned with some authors, like Sinha et al. (2018), that affirms that "any young people are entering adulthood without adequate financial capabilities to ensure their future well-being and that of their children."

Greenspan in 2002 gave some tips on how to teach kids about cash when discussing this new millennium. For the young adults, those are valuable ones considering the present time and the results of this research. The author affirms that this group must be encouraged:

- older teens or young adults to explore the cost of setting up their apartment;

- to shop for the best interest in savings as well as understand cost credit;

- to set financial goals, improve shopping skills, learn how to make a consumer complaint, and understand investments.

\section{Next steps and future work}

A detailed statistical analysis is on course to verify differences among male/ female and workers/ not workers answers in this sample. That pointed out that it may be necessary to get a broader sample, considering social-economic clusters, in a new formulary.

From this data collection and understanding better about the younger adults' attitudes with money, the next step is to analyze banks and financial institutions' advertisements, checking if it fits the expectancies of this public. Another proposal for future work is to review some of the promotional material aligning with plain language aspects. 
An experimental research phase was initiated, in which the results presented in this work are investigated using eye-tracking. The focus is on the analysis of the comprehensibility of the financial information presented on bank websites.

\section{Acknowledgements}

The authors would like to thank the Brazilian National Council for Scientific and Technological Development (CNPq) and the Coordenação de Aperfeiçoamento de Pessoal de Nível Superior - Brasil (CAPES) - Finance Code 001 for the financing that supported the study.

\section{References}

Ali, P., MacRae, C., \& Ramsay, I. (2014). Financial Literacy and Financial Decision-Making of Australian Secondary School Students. Australian Business Law Review, 42(3), 228-233, 2014

Arnett, J. J., \& Schwab, J. (2012). The Clark University poll of emerging adults, Thriving, struggling, and hopeful. Worcester, MA: Clark University.

Bandura, A. (1989) Human agency in social cognitive theory. American Psychologist, 44(9), 1175-1184. https://doi.org/10.1037/0003-066X.44.9.1175

Becchetti, L., Caiazza, S., \& Coviello, D. (2013) Financial education and investment attitudes in high schools: evidence from a randomized experiment. Applied Financial Economics, 23(10), 817-836. https://doi.org/10.1080/09603107.2013.767977

Brown, M., Van der Klaauw, W., Wen, J., \& Zafar, B. (2013) Financial education and the debt behavior of the young. Federal Reserve Bank of New York Staff Report No. 634. https://doi.org/10.2139/ssrn.2334889

Carlin, B., \& Robinson, D.T. (2012a) What does financial literacy training teach us? Journal of Economic Education, 43(3), 235-247. https://doi.org/10.1080/00220485.2012.686385

Carlin, B., \&Robinson, D.T (2012b) Financial education and timely decision support: lessons from Junior Achievement. American Economic Review, 102(3), 305-308. https://doi.org/10.1257/aer.102.3.305

Dul, J. et al. (2012). A strategy for human factors/ergonomics: developing the discipline and profession. Ergonomics, 55(4), 377-395. https://doi.org/10.1080/00140139.2012.661087

Greenspan, A. (2002). Financial literacy: A tool for economic progress. The Futurist, Jul/Aug, 36(4), Technology Collection. pp. 37-41.

Hancock, P. (2018). On the Design of Time. Ergonomics in design, April 2018. Pp. 4-9. by Human Factors and Ergonomics Society. All rights reserved. https://doi.org/10.1177/1064804617735018

Huston, S. (2010) Measuring Financial Literacy. The Journal of Consumer Affairs, 44(2), 296-316. https://doi.org/10.1111/j.1745-6606.2010.01170.x 


\section{Macrothink}

Journal of Studies in Education

ISSN 2162-6952

IBGE. (2019). Pesquisa Nacional por Amostra de Domicílios Contínua. Educação. IBGE. Coordenação de Trabalho e Rendimento. Retrieved from https://biblioteca.ibge.gov.br/index.php/biblioteca-catalogo?view=detalhes\&id=2101657.

Accessed in 6 Feb 2021.

Inaf Brasil. (2018). Resultados preliminares. Estudo especial sobre alfabetismo e mundo do $\begin{array}{lllll}\text { trabalho. São } & \text { Paulo. } & \text { Retrieved } & \text { from }\end{array}$ http://acaoeducativa.org.br/wp-content/uploads/2018/08/Inaf2018_Relat\%C3\%B3rio-Resulta dos-Preliminares_v08Ago2018.pdf Accessed in 18 Feb 2021.

Lowe, K., \& Arnett, J. (2020). Failure to Grow Up, Failure to Pay? Parents' Views of Conflict Over Money With Their Emerging Adults. Journal of Family Issues, 41(3), 359-382. https://doi.org/10.1177/0192513X19876061

Lührmann, M., Serra-Garcia, M., \& Winter, J. (2015). Teaching teenagers in finance: does it work? Journal of Banking and Finance, 54, 160-174. https://doi.org/10.1016/j.jbankfin.2014.11.009

Lusardi, A., \& Mitchell, O. (2011). Financial literacy around the world: an overview. Journal of Pension Economics and Finance, 10, 497-508. https://doi.org/10.1017/S1474747211000448

Lusardi, A., \& Mitchell, O. (2007). Baby Boomer retirement security: The roles of planning, financial literacy, and housing wealth. Journal of Monetary Economics, 54(1), 205-224. https://doi.org/10.1016/j.jmoneco.2006.12.001

Lusardi, A. (2012). Numeracy, financial literacy, and financial decision-making. Numeracy, 5(1), Article 2. https://doi.org/10.3386/w17821

Lusardi, A. (2015) Financial literacy: Do people know the ABCs of finance? Public Understanding of Science, 24(3), 260-271. https://doi.org/10.1177/0963662514564516

Lusardi, A. et al. (2017) Visual tools and narratives: new ways to improve financial literacy. PEF, 16(3), 297-323, July. https://doi.org/10.1017/S1474747215000323

OECD (2019) Education at a Glance 2019: OECD Indicators, OECD Publishing, Paris. https://doi.org/10.1787/f8d7880d-en

Parker, K., \& Patton, E. (2013). The sandwich generation: Rising financial burdens for middle-aged Americans. Washington, DC: Pew Research Center.

Schoeni, R. F., \& Ross, K. E. (2005). Material assistance from families during the transition to adulthood. In R. A. Settersten, F. F. Furstenberg, \& R. G. Rumbaut (Eds.), On the frontier of adulthood: Theory, research, and public policy (pp. 396-416). Chicago, IL: University of Chicago Press. https://doi.org/10.7208/chicago/9780226748924.003.0012

Sinha, G. et al. (2018). Patterns of financial attributes and behaviors of emerging adults in the United States. Children and Youth Services Review, 93, 178-185. https://doi.org/10.1016/j.childyouth.2018.07.023 


\section{Macrothink}

Journal of Studies in Education

ISSN 2162-6952

2021, Vol. 11, No. 2

UNESCO. (2019). International Literacy Day 2019. Revisiting literacy and multilingualism. Background paper. Retrieved from https://unesdoc.unesco.org/ark:/48223/pf0000370416. Accessed 1 Feb 2021.

Walstad, W. B. et al. (2010) The effects of financial education on the financial knowledge of high school students. Journal of Consumer Affairs, 44(2), 336-357. https://doi.org/10.1111/j.1745-6606.2010.01172.x

Winsall M. and al. (2019) Designing Online Interventions in Consideration of Young People's Concepts of Well-Being: Exploratory Qualitative Study. JMIR Hum Factors, 6(1), e10106. https://doi.org/10.2196/10106 